\title{
Recyclable nickel catalysed Suzuki-Miyaura reaction in the presence of polyethyleneimine under phosphine-free conditions in ethylene glycol ${ }^{\#}$
}

\author{
NOOREDIN GOUDARZIAN ${ }^{\mathrm{a}, *}$, MOHAMMAD GHOLINEJAD $^{\mathrm{b}, *}$ and PARISA GHAHRAMANI ${ }^{\mathrm{c}}$ \\ ${ }^{a}$ Chemistry Department, Islamic Azad University, Shiraz Branch, Shiraz, Iran, P.O. Box 71955-149 \\ ${ }^{\mathrm{b}}$ Chemistry Department, Shiraz University, Shiraz, Iran \\ 'Industrial Chemistry Department, Technical Institute, Shiraz, Iran \\ e-mail: n.goodarzian@yahoo.com; ngo@iaushiraz.net; gholinejad@shirazu.ac.ir
}

MS received 24 October 2010; revised 13 January 2011; accepted 11 April 2011

\begin{abstract}
In this report, Suzuki-Miyaura coupling reaction was performed in the presence of polyethyleneimine (PEI) as ligand, $\mathrm{NiCl}_{2} \cdot 6 \mathrm{H}_{2} \mathrm{O}$ and $\mathrm{K}_{2} \mathrm{CO}_{3}$ in ethylene glycol at $80-100^{\circ} \mathrm{C}$ under phosphinefree conditions. By this method, structurally different aryl bromides and iodides were reacted with phenylboronic acid and potassium phenyltrifluoroborate. Under these simple reaction conditions a different biaryl derivatives have been prepared in high to excellent yields. Recycling experiments showed that catalyst can be used as recyclable catalyst in the Suzuki-Miyaura cross-coupling reactions.
\end{abstract}

Keywords. Suzuki-Miyaura; polyethyleneimine; nickel; Phoshphine free; recyclable.

\section{Introduction}

Transition-metal catalysed cross-coupling reactions are powerful tools for the formation of new carbon-carbon bonds. Among the large group of transition metals, palladium complex together with (phosphorous) ligands is the most popular catalytic system. ${ }^{1-7}$ Palladium catalysed coupling of aryl halides with boronic acids known as the Suzuki-Miyaura coupling reaction. This is one of the most versatile and a fast growing methodologies for the selective formation of $\mathrm{C}-\mathrm{C}$ bond, in particular for production of biaryls. Biaryl moieties are found in a variety of pharmaceuticals, liquid crystals, conductive polymers and natural products. For these purposes, this reaction has become very popular in both academic and industrial laboratories. ${ }^{8-12}$

However, palladium is an expensive metal; description of commercial processes based on the Pd are less attractive for industrial scales. Therefore, development of palladium-free catalysts for Suzuki-Miyaura coupling reaction are attractive due to both economical and environmental concerns. ${ }^{13-25}$ Also, most of the used phosphorus ligands in these reactions, have drawbacks of difficulty of synthesis, poor thermal and air stability

\footnotetext{
*For correspondence

${ }^{\text {\# }}$ This paper is dedicated to Professor Habib Firouzabadi on the occasion of his 68th birthday
}

which are the main reasons for the growing interest in N-coordinating ligands for catalysts in coupling reactions. Indeed, many $\mathrm{N}$-based ligands have been reported to be efficient for the Suzuki cross-coupling reactions. ${ }^{26-32}$

Recently, different homogeneous and heterogeneous nickel catalysts have been used for Suzuki-Miyaura coupling. ${ }^{33-38}$ Homogeneous catalysis encounters number of drawbacks such as; reuse of the catalyst, loss of expensive metals and ligands. In addition, contamination of the products by the metal residues, even after purification step, is a sharp problem for large-scale operation in pharmaceutical industries. ${ }^{39-51}$

Polyethyleneimine has been widely used for preparation of polymer supported phase-transfer catalysts. Its physicochemical incompatibility with solvents and substrates most often leads to high efficiency and reactivity. Recently we have designed a synthetic polar polymeric supports such as polyvinylpyridine and polyethyleneimine. These polymers have been used as co-solvent type catalysts for nucleophylic displacement reactions under biphase and triphase conditions. Also, we used from these polymers as a support for the solid phase synthesis of several organic compounds, metal complex and for the preparation of a number of polymer supported reagents. These supported systems were found to have different characteristics in terms of polarity, salvations and reactivity compared to the commonly used monomeric form. ${ }^{52-56}$ 


\section{Experimental}

\subsection{General remarks}

NMR spectra were recorded on a Bruker Avance DPX250. The purity of the products and the progress of the reactions were accomplished by TLC on silica-gel polygram SILG/UV254 plates or GC analysis using a 3-meter length column packed with DC-200 stationary phase.

\subsection{General experimental procedure for the Suzuki-Miyaura reaction}

In $5 \mathrm{~mL}$ flask containing ethylene glycol $(2 \mathrm{~mL})$, was added polyethyleneimine (300 mg) and stirred until solving in 80 or $100^{\circ} \mathrm{C}$. To the resulting solution were added $\mathrm{NiCl}_{2} \cdot 6 \mathrm{H}_{2} \mathrm{O}(1 \mathrm{~mol} \%)$ aryl halide $(1 \mathrm{mmol})$, phenylboronic acid or Potassium phenyltrifluoroborate (1.5 mmol) and $\mathrm{K}_{2} \mathrm{CO}_{3}(1.5 \mathrm{mmol})$. The progress of the reaction was monitored by TLC or GC analyses. After completion of the reaction, the reaction mixture was allowed to cool down to room temperature and extracted with ethyl acetate or diethyl ether $(3 \times 2 \mathrm{~mL})$ and the upper organic phase was separated, washed with $3 \mathrm{~mL}$ water, dried over anhydrous $\mathrm{MgSO}_{4}$ and evaporated. Further purification was performed by column chromatography (EtOAc/n-hexane) to obtain the desired coupling product. ${ }^{57-59}$

\subsection{Recycling of the catalyst}

After completion of the reaction of iodobenzene (1 mmol) with phenylboranic acid $(1.5 \mathrm{mmol})$, the reaction mixture was cooled down to room temperature and washed with diethyl ether $(3 \times 2 \mathrm{~mL})$ to extract product and unreacted material. Then residue containing of polymer and $\mathrm{NiCl}_{2} \cdot 6 \mathrm{H}_{2} \mathrm{O}$ was reused for the similar reaction.

\subsection{Characterization data of compounds}

1a ${ }^{60}:{ }^{1} \mathrm{H}$ NMR $\left(250 \mathrm{MHz}, \mathrm{CDCl}_{3}\right) \delta(\mathrm{ppm}): 7.33-7.64$ (m, $10 \mathrm{H})$.

1b $^{60}$ : ${ }^{1} \mathrm{H}$ NMR (250 MHz, $\left.\mathrm{CDCl}_{3}\right) \delta(\mathrm{ppm}): 7.51-7.57$ (m, 4H), $7.41(\mathrm{t}, 1 \mathrm{H}, J=7.2), 7.28(\mathrm{t}, 1 \mathrm{H}, J=7.2), 6.98$ $(\mathrm{d}, 2 \mathrm{H}, J=7.5), 3.85(\mathrm{~s}, 3 \mathrm{H}) ;{ }^{13} \mathrm{C} \mathrm{NMR}(62.9 \mathrm{MHz}$, $\left.\mathrm{CDCl}_{3}\right) \delta$ (ppm): 159.2, 140.9, 133.8, 128.8, 128.4, 128.2, 127.1, 114.3, 55.3.

1c ${ }^{60}:{ }^{1} \mathrm{H}$ NMR $\left(250 \mathrm{MHz}, \mathrm{CDCl}_{3}\right) \delta(\mathrm{ppm}): 8.19(\mathrm{~d}, 2 \mathrm{H}$, $J=9.0), 7.63$ (d, 2H, $J=9.0), 7.53$ (dd, $2 \mathrm{H}, J=7.5$,
1.5), 7.36-7.43 (m, 3H); ${ }^{13} \mathrm{C}$ NMR (62.9 $\mathrm{MHz}$, $\left.\mathrm{CDCl}_{3}\right) \delta(\mathrm{ppm}): 147.6,147.0,138.7,129.1,128.9$, 127.7, 127.3, 124.1.

1d $^{60}:{ }^{1} \mathrm{H}$ NMR $\left(250 \mathrm{MHz}, \mathrm{CDCl}_{3}\right) \delta(\mathrm{ppm}): 7.73(\mathrm{~m}$, 2H), 7.39-7.59 (m, 7H), $2.43(\mathrm{~s}, 3 \mathrm{H}) ;{ }^{13} \mathrm{C}$ NMR (62.9 MHz, $\left.\mathrm{CDCl}_{3}\right) \delta(\mathrm{ppm}): 142.0,141.3,135,130.4$, 129.9, 129.3, 128.9, 128.2, 127.6, 126.4, 125.9, 20.6.

1e $^{61}:{ }^{1} \mathrm{H}$ NMR $\left(250 \mathrm{MHz}, \mathrm{CDCl}_{3}\right) \delta(\mathrm{ppm}): 7.53-7.49$ (m, 2H). 7.26-7.14 (m, 5H), 6.96-6.86 (m, 1H).

1f $^{60}:{ }^{1} \mathrm{H}$ NMR $\left(250 \mathrm{MHz}, \mathrm{CDCl}_{3}\right) \delta(\mathrm{ppm}): 8.07-7.95$ $(\mathrm{m}, 3 \mathrm{H}), 7.61-7.53(\mathrm{~m}, 9 \mathrm{H}) ;{ }^{13} \mathrm{C} \mathrm{NMR}(62.9 \mathrm{MHz}$, $\left.\mathrm{CDCl}_{3}\right) \delta$ (ppm): 140.9, 140.4, 133.9, 131.7 129.8, 128.8, 128.4, 127.4, 127.3, 127.0, 126.7, 126.1, 125.9, 125.5 .

1g ${ }^{60}:{ }^{1} \mathrm{H}$ NMR $\left(250 \mathrm{MHz}, \mathrm{CDCl}_{3}\right) \delta(\mathrm{ppm}): 7.73(\mathrm{~m}$, 2H), 7.59-7.39 (m, 7H), 2.43 (s, 3H).

1h: ${ }^{1} \mathrm{H}$ NMR $\left(250 \mathrm{MHz}, \mathrm{CDCl}_{3}\right) \delta(\mathrm{ppm}): 7.50-7.18$ (m, 7H), 6.85-6.81(m, 2H), $4.61(\mathrm{~s}, 1 \mathrm{H})$.

1i $^{62}:{ }^{1} \mathrm{H}$ NMR $\left(250 \mathrm{MHz}, \mathrm{CDCl}_{3}\right) \delta(\mathrm{ppm}): 8.85(\mathrm{~s}, 1 \mathrm{H})$, 8.57 (s, 1H), 7.84 (d, $1 \mathrm{H}, J=8.0), 7.33-7.57$ (m, $6 \mathrm{H})$; ${ }^{13} \mathrm{C} \mathrm{NMR}\left(62.9 \mathrm{MHz}, \mathrm{CDCl}_{3}\right) \delta(\mathrm{ppm}): 148.3,148.1$, 137.7, 136.7, 134.4, 129.0, 128.1, 127.1, 123.6.

1j $^{62}$ : ${ }^{1} \mathrm{H}$ NMR (250 MHz, $\left.\mathrm{CDCl}_{3}\right) \delta$ (ppm): 7.45-7.75 $(\mathrm{m}, 9 \mathrm{H}) ;{ }^{13} \mathrm{C} \mathrm{NMR}\left(62.9 \mathrm{MHz}, \mathrm{CDCl}_{3}\right) \delta$ (ppm): 141.8, 136.2, 132.4, 128.6, 126.9, 119.0, 110.5.

1k ${ }^{60}:{ }^{1} \mathrm{H}$ NMR $\left(250 \mathrm{MHz}, \mathrm{CDCl}_{3}\right) \delta(\mathrm{ppm}): 7.29-7.50$ $(\mathrm{m}, 9 \mathrm{H}) ;{ }^{13} \mathrm{C}$ NMR $\left(62.9 \mathrm{MHz}, \mathrm{CDCl}_{3}\right) \delta(\mathrm{ppm}): 139.1$, 138.4, 133.7, 129.0, 128.7, 128.3, 127.5, 126.9 .

\section{Results and discussion}

Polyethyleneimine has been produced on the industrial scale since 1938 which is obtained mainly by the polymerization of aziridine ${ }^{63}$ (figure 1).

In this article, we report using of polyethyleneimine (PEI) as ligand in the presence of $\mathrm{NiCl}_{2} \cdot 6 \mathrm{H}_{2} \mathrm{O}$ for the successful recyclable Suzuki-Miyaura coupling reaction in ethylene glycol under phosphine-free and mild reaction conditions. Polyethyleneimine is stable, cheap, non-toxic polymer, and its handling in the presence of $\mathrm{NiCl}_{2} \cdot 6 \mathrm{H}_{2} \mathrm{O}$ for Suzuki coupling does not need special precautions and inert atmosphere.

Optimized reaction conditions were achieved by the reaction of 4-iodoanisole ( $1 \mathrm{mmol})$ as a model compound with phenylboranic acid $(1.5 \mathrm{mmol})$ in the presence of $\mathrm{NiCl}_{2} \cdot 6 \mathrm{H}_{2} \mathrm{O}$ (1 $\left.\mathrm{mol} \%\right)$, polyethyleneimine

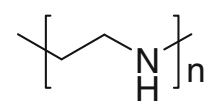

Figure 1. Polyethyleneimine. 
Table 1. Screening of different solvents upon the reaction of 4-iodoanisole with phenylboranic acid.

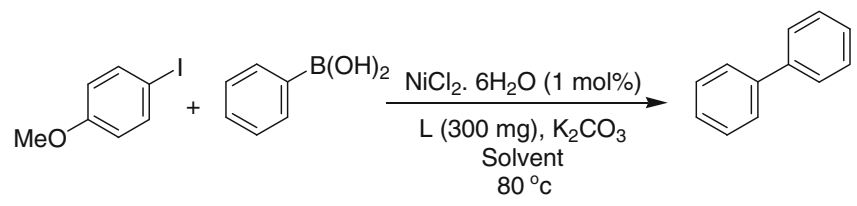

\begin{tabular}{llc}
\hline Entry & Solvent & Isolated yield\% \\
\hline 1 & DMF & 55 \\
2 & Dioxane & 10 \\
3 & Toluene & trace \\
4 & EG & 91 \\
5 & NMP & 62 \\
6 & Water & 25 \\
\hline
\end{tabular}

(PEI) (300 mg) and $\mathrm{K}_{2} \mathrm{CO}_{3}(1.5 \mathrm{mmol})$ in ethylene glycol. In order to show the effect of solvents upon the reaction, model reaction was studied in the presence of different solvents such as Toluene, DMF, THF, NMP and water (table 1).

Therefore, the subsequent reactions were performed in EG which possesses negligible vapor pressure, thermally stable, not expensive, and in comparison with many other organic solvents shows low toxicity. Recently, such similar effect of PEG has been reported for the Suzuki coupling reaction catalysed by nickel, copper and palladium catalysts. ${ }^{64-66}$

Inorder to show the effect of polyethyleneimine (PEI) in this reaction, we performed the reaction of 4-iodoanisole with phenylboronic acid in the presance of $\mathrm{NiCl}_{2} .6 \mathrm{H}_{2} \mathrm{O}$ and $\mathrm{K}_{2} \mathrm{CO}_{3}$ in ethylene glycole in the absence of polyethyleneimine at $80^{\circ} \mathrm{C}$. The results of this study showed that in the absence of the polyethyleneimine the reaction was slugish and only $53 \%$ GC yield was obtained. Also, important role of polyethyleneimine was studied by UV-Vis spectra which shows conversion of $\mathrm{Ni}(\mathrm{II})$ to $\mathrm{Ni}(0)$ in the presence of polyethyleneimine by the disappearance
Table 2. Reactions of aryl iodides and bromides with phenylboranic acid and potassium phenyltrifluoroborate in the presence of $\mathrm{NiCl}_{2} \cdot 6 \mathrm{H}_{2} \mathrm{O}$ and Polyethyleneimine (PEI) at $80-100^{\circ} \mathrm{C}$.

\begin{tabular}{|c|c|c|c|c|c|c|}
\hline Entry & ArX & $\mathrm{R}$ & $\mathrm{T}\left({ }^{\circ} \mathrm{C}\right)$ & $\begin{array}{c}\text { Time } \\
\text { (h) }\end{array}$ & Product & $\begin{array}{l}\text { Isolated } \\
\text { yield } \%\end{array}$ \\
\hline 1 & & $\mathrm{~B}(\mathrm{OH})_{2}$ & 80 & 2 & 1a & 91 \\
\hline 2 & & $\mathrm{~B}(\mathrm{OH})_{2}$ & 80 & 12 & $1 b$ & 90 \\
\hline 3 & & $\mathrm{~B}(\mathrm{OH})_{2}$ & 80 & 1 & 1c & 93 \\
\hline 4 & & $\mathrm{~B}(\mathrm{OH})_{2}$ & 80 & 10 & 1d & 85 \\
\hline 5 & & $\mathrm{~B}(\mathrm{OH})_{2}$ & 80 & 4 & 1e & 83 \\
\hline 6 & & $\mathrm{~B}(\mathrm{OH})_{2}$ & 80 & 9 & 1f & 84 \\
\hline 7 & & $\mathrm{~B}(\mathrm{OH})_{2}$ & 80 & 10 & $1 \mathrm{~g}$ & 82 \\
\hline 8 & & $\mathrm{~B}(\mathrm{OH})_{2}$ & 80 & 10 & $1 \mathrm{~h}$ & 89 \\
\hline 9 & & $\mathrm{~B}(\mathrm{OH})_{2}$ & 100 & 14 & $1 a$ & 84 \\
\hline 10 & & $\mathrm{~B}(\mathrm{OH})_{2}$ & 100 & 17 & 1d & 80 \\
\hline 11 & & $\mathrm{~B}(\mathrm{OH})_{2}$ & 100 & 12 & $1 \mathbf{i}$ & 75 \\
\hline 12 & & $\mathrm{~B}(\mathrm{OH})_{2}$ & 100 & 9 & $\mathbf{1 j}$ & 88 \\
\hline 13 & & $\mathrm{~B}(\mathrm{OH})_{2}$ & 100 & 7 & 1c & 90 \\
\hline 14 & & $\mathrm{~B}(\mathrm{OH})_{2}$ & 100 & 14 & $1 \mathrm{k}$ & 80 \\
\hline 15 & & $\mathrm{~B}(\mathrm{OH})_{2}$ & 100 & 48 & 1d & trace \\
\hline 16 & & $\mathrm{BF}_{3} \mathrm{~K}$ & 80 & 2.2 & 1a & 90 \\
\hline 17 & & $\mathrm{BF}_{3} \mathrm{~K}$ & 80 & 13 & $1 b$ & 86 \\
\hline 18 & & $\mathrm{BF}_{3} \mathrm{~K}$ & 80 & 10 & 1c & 86 \\
\hline 19 & & $\mathrm{BF}_{3} \mathrm{~K}$ & 100 & 16 & 1a & 76 \\
\hline 20 & & $\mathrm{BF}_{3} \mathrm{~K}$ & 100 & 12 & $\mathbf{1 i}$ & 78 \\
\hline 21 & & $\mathrm{BF}_{3} \mathrm{~K}$ & 100 & 10 & $1 \mathbf{j}$ & 81 \\
\hline
\end{tabular}

of the peaks related to $\mathrm{Ni}(\mathrm{II})$ at 400 and $700 \mathrm{~nm}^{67}$ (figure 2).

We applied the optimized reaction conditions for the Suzuki-Miyaura coupling of structurally different aryl iodides and bromides with phenylboronic acid and potassium phenyltrifluoroborate at 80 or $100^{\circ} \mathrm{C}$ (table 2).

As it is evident from the results tabulated in table 2 (entries 1-9), different aryl iodides were reacted with phenylboronic acid at $80^{\circ} \mathrm{C}$ in appropriate reaction times. The desired biphenyl compounds were isolated in $82-93 \%$ yields. We also studied the applicability (a)

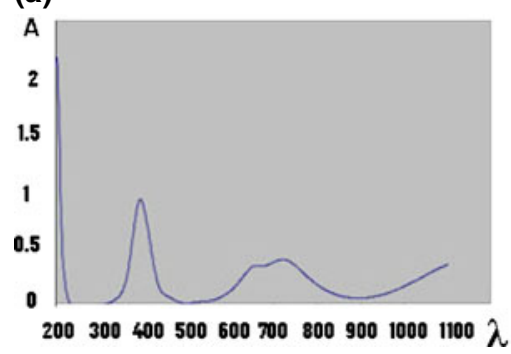

(b)

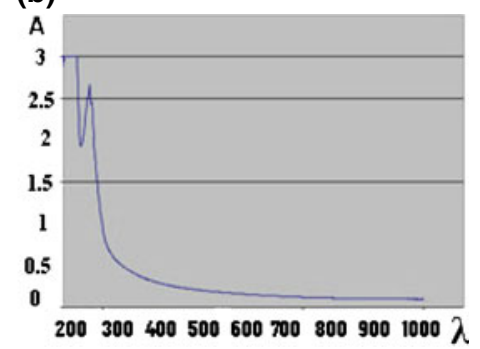

Figure 2. (a) UV-Vis of $\mathrm{NiCl}_{2} \cdot 6 \mathrm{H}_{2} \mathrm{O}$, (b) UV-Vis of $\mathrm{NiCl}_{2} \cdot 6 \mathrm{H}_{2} \mathrm{O}$ in the presence of PEI. 
of this catalyst for the reaction of arylbromides with phenylboronic acid at $100^{\circ} \mathrm{C}$, the reactions proceeded well and desired products obtained in $75-90 \%$ isolated yields. We also studied the applicability of method for the reaction of aryl chlorides with phenylboronic acid; for this purpose, reaction of 4-chlorotoluene with phenylboronic acid at $100^{\circ} \mathrm{C}$ was studied. The results of study showed that the reaction did not proceed and starting material was isolated intact after appropriate reaction time.

Potassium organotrifluoroborates are another substitute for boronic acids in the Suzuki-Miyaura coupling reactions. In recent years, there has been increased interest in the use of potassium organotrifluoroborates as coupling partners for this reaction. ${ }^{68}$ In order to show the application of our method, we studied the coupling of iodobenzene, 4-iodoanisole, 4-iodotoluene, bromobenezene, 3-bromopyridine and 4-bromobenzonitrile with potassium phenyltrifluoroborate under the optimized reaction conditions. The reactions proceeded successfully and afforded the corresponding cross-coupled products in high to excellent yields (78-90\%) (table 2, entries 16-21). A proposed mechanism for $\mathrm{C}-\mathrm{C}$ bond formation via Suzuki-Miyaura reaction polyethyleneimine (PEI) and $\mathrm{NiCl}_{2} \cdot 6 \mathrm{H}_{2} \mathrm{O}$ in the presence of a base is presented in scheme 1.

Recycling of the reaction was also studied. For this propose, after completion of the reaction of iodobenzene with phenylboronic acid, reaction mixture was allowed to cool down to room temperature, washed with diethyl ether and residue that contain nickel and polyethyleneimine, was reused for another reaction at the same reaction conditions. This recycling was

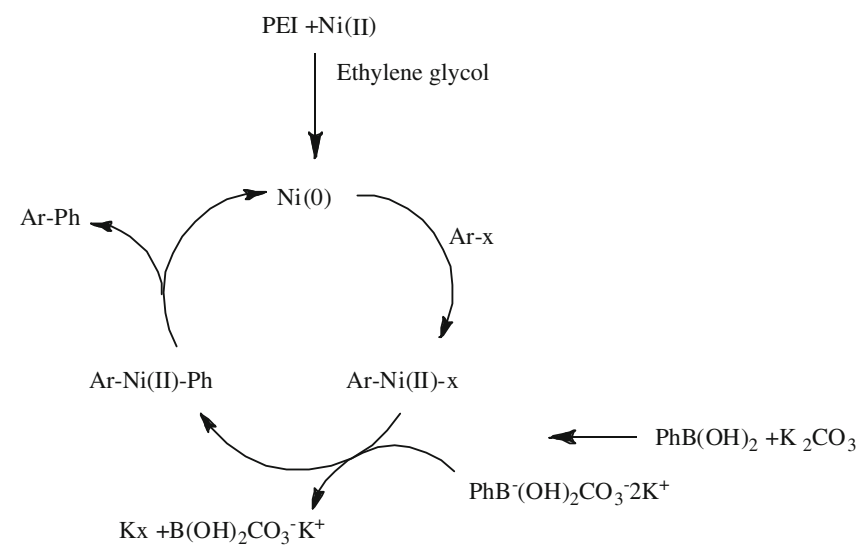

Scheme 1. Proposed mechanism for nickel catalysed Suzuki-Miyaura coupling reaction in the presence of polyethyleneimine (PEI).
Table 3. Recycling of the catalyst for the reaction of iodobenzene with phenylboranic acid.

\begin{tabular}{lcc}
\hline Run & Time (min) & Isolated yields\% \\
\hline 1 & 4 & 91 \\
2 & 4 & 90 \\
3 & 4 & 88 \\
4 & 4 & 86 \\
\hline
\end{tabular}

repeated for four times without significant loss of yield (table 3). This result supports that the nickel leaching should occur in low quantity. ICP analysis of nickel content of diethyl ether after first recycling run showed $1.02 \mathrm{ppm}$ of nickel amount in the ether phase.

\section{Conclusions}

In this article, we have successfully used from $\mathrm{NiCl}_{2}$. $6 \mathrm{H}_{2} \mathrm{O}$ in the presence of polyethyleneimine in ethylene glycol as an efficient media for phosphine-free SuzukiMiyaura coupling of different aryl iodides and bromides with phenylboronic acid and Potassium phenyltrifluoroborate at 80 and $100^{\circ} \mathrm{C}$. The catalyst can be applied for large-scale operation and is also recyclable. The recycling was repeated for four times without considerable loss of its catalytic activity.

\section{Acknowledgements}

We thank the Islamic Azad University-Shiraz branch, for supporting this work. We also thank Dr. Diego Alonso for his valuable help.

\section{References}

1. Negishi E and de Meijere A 2002 Handbook of organopalladium chemistry for organic synthesis (New York: Wiley-Interscience)

2. Miyaura N 2000 Cross-coupling reactions. A practical guide (Berlin: Springer-Verlag)

3. Beller M and Bolm C 2004 Transition metals for organic synthesis, building block and fine chemicals, 2nd Ed., (Weinheim: Wiley-VCH)

4. Alonso D A and Najera C 2010 Chem. Soc. Rev. 392891

5. Zapf A and Beller M 2002 Top. Catal. 19101

6. Tucker C E and de Vries J G. 2002 Top. Catal. 19111

7. Brase S, Kirchhoff J H and Kobberling J 2003 Tetrahedron 59885

8. Miyaura N, Yamada K and Suzuki A 1979 Tetrahedron Lett. 203437 
9. Miyaura N and Suzuki A 1979 J. Chem. Soc. Chem. Commun. 866

10. Miyaura N and Suzuki A 1995 Chem. Rev. 952457

11. Nicolaou K C, Bulger P G and Sarlah D 2005 Angew. Chem. Int. Ed. 444442

12. Kotha S, Lahiri K and Kashinath D 2002 Tetrahedron 58 9633

13. Xu L, Li B-J, Wu Z-H, Lu X-Y, Guan B-T, Zhao K-Q and Shi Z-J 2010 Org. Lett. 12884

14. Cho C S and Tran N T 2009 Catal. Commun. 11191

15. Kuroda J -I, Inamoto K, Hiroya K and Doi T 2009 Eur. J. Org. Chem. 142251

16. Chen C and Yang L-M 2007 Tetrahedron Lett. 482427

17. You E, Li P and Wang L 2006 Synthesis 91465

18. González-Bobes F and Fu G C 2005 J. Am. Chem. Soc. 1285360

19. Borhade S R and Waghmode S B 2010 Indian J. Chem. $B 49565$

20. Gracias V and Iyengar R 2005 Chemtracts 18 339-348

21. Tang Z Y and Hu Q S 2004 Adv. Synth. Catal. 346 1635

22. Tang Z Y, Spinella S and Hu Q S 2006 Tetrahedron Lett. 472427

23. Lipshutz B H, Sclafani J A and Blomgren P A 2000 Tetrahedron $\mathbf{5 6} 2139$

24. Leadbeater N E and Resouly S M 1999 Tetrahedron 55 11889

25. Indolese A F 1997 Tetrahedron Lett. 383513

26. Grasa G A, Viciu M S, Huang J, Zhang C, Trudell M L and Nolan S P 2002 Organometallics 212866

27. Chahen L, Therrien B and Süss-Fink G 2007 Eur. J. Inorg. Chem. $\mathbf{5 0 4 5}$

28. Alonso, D A, Najera C and Pacheco M C 2000 Org. Lett. 21823

29. Chahen L, Therrien B and Süss-Fink G 2006 J. Organomet. Chem. 6914257

30. Tao B and Boykin D W 2002 Tetrahedron Lett. 43 4955

31. Tao B and Boykin D W 2004 J. Org. Chem. 694330

32. Tao B and Boykin D W 2003 Tetrahedron Lett. 447993

33. Reetz M T, Breinbauer R and Wanninger K 1996 Tetrahedron Lett. 374499

34. Galland J P, Savignac M and Genêt J P 1999 Tetrahedron Lett. 402323

35. Zim D, Lando, V R, Dupont J and Monteiro A L 2001 Org. Lett. 33049

36. Guo Y, Young D and Hor T S A 2008 Tetrahedron Lett. 495620

37. Zim D and Monteiro A L 2002 Tetrahedron Lett. 43 4009

38. Ramarao C, Ley S V, Smith S C, Shirley, I M and De Almeida N 2002 Chem. Commun. 1132

39. Ley S V, Ramarao C, Gordon R S, Holmes A B, Morrison A J, McConvey I F, Shirley I M, Smith, S C, Smith M D 2002 Chem. Commun. 1134
40. Trzeciak A M, Mieczynska E, Ziolkowski W, Bukowska A, Noworol J and Okal J 2008 New J. Chem. 321124

41. Akiyama R and Kobayashi S 2003 J. Am. Chem. Soc. 1253412

42. Okamoto K, Akiyama R and Kobayashi S 2004 Org. Lett. 61987

43. Nishio R, Sugiura M and Kobayashi S 2005 Org Lett. 7 4831

44. Hagio H, Sugiura M and Kobayashi S 2006 Org. Lett. 8 375

45. Akiyama R and Kobayashi S 2009 Chem. Rev. 109594

46. Kim J-H, Kim J-W, Shokouhimehr M and Lee Y-S 2005 J. Org. Chem.70 6714

47. Byun J-W and Lee Y -S 2004 Tetrahedron Lett. 451837

48. Shokouhimehr M, Kim J-H and Lee Y-S 2006 Synlett. 4 618

49. Schweizer S, Becht J M and Drian C L 2010 Tetrahedron 66765

50. Schweizer S, Becht J M and Drian C L 2007 Org. Lett. 93777

51. Schweizer S, Becht J M and Drian C L 2007 Adv. Synth. Catal. 3491150

52. Goudarzian N and Hosini S 1996 Poly. Int. 3961

53. Firouzabadi H, Tamami B, Goudarzian N 1991 Synth. Commun. 212275

54. Firouzabadi H, Tamami B, Goudarzian N, Hatam M and Mansour M L 1991 Synth. Commun. 212077

55. Tamami B and Goudarzian N 1992 Eur. Polym. J. 28 1035

56. Tamami B and Goudarzian N 1994 J. Chem. Soc. Chem. Commun. 1079

57. Zhou W-J, Wang, K-H, and Wang J-X 2009 Adv. Synth. Catal. 3511378

58. Firouzabadi H, Iranpoor $\mathrm{N}$ and Gholinejad M $2010 A d v$. Synth. Catal. 352119

59. Firouzabadi H, Iranpoor N, Gholinejad M and Hoseini J 2011 Adv. Synth. Catal. 353125

60. Shi S and Zhang Y 2007 J. Org. Chem. 725927

61. Firouzabadi H, Iranpoor N and Gholinejad M $2010 \mathrm{~J}$. Orgmetal. Chem. 6952093

62. Feuerstein M, Doucet M and Santelli M 2003 J. Organomet. Chem. $\mathbf{6 8 7} 327$

63. Zhuk D S, Gembitskii P A and Kargin V A 1965 Russ. Chem. Rev. 34515

64. Cho C S and Tran N T 2009 Catal. Commun. 11 191195

65. Mao J, Guo J, Fang F and Ji S J 2008 Tetrahedron 64 3905

66. Yin L, Zhang Z-h and Wang Y -m 2006 Tetrahedron 62 9359

67. Kryatov S V, Mohanraj B S, Tarasov V V, Kryatova O P, Rybak-Akimova E V, Nuthakki B, Rusling J F, Staples R J, Nazarenko A Y 2002 Inorg. Chem. 41923

68. Molander G A and Canturk B 2009 Angew. Chem. Int. Ed. 489240 